University of South Carolina

Scholar Commons

$7-2011$

\title{
Results of the "Active by Choice Today" (ACT) Randomized Trial for Increasing Physical Activity in Low-Income and Minority Adolescents
}

\author{
Dawn K. Wilson \\ M. Lee Van Horn \\ Heather Kitzman-Ulrich \\ Ruth P. Saunders \\ Russell R. Pate \\ University of South Carolina - Columbia, rpate@mailbox.sc.edu \\ Follow this and additional works at: https://scholarcommons.sc.edu/

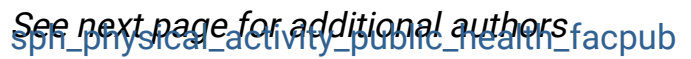 \\ Part of the Public Health Commons
}

\section{Publication Info}

Postprint version. Published in Health Psychology, Volume 30, Issue 4, 2011, pages 463-471. Wilson, D. K., Van Horn, M. L., Kitzman-Ulrich, H., Saunders, R., Pate, R., Lawman, H. G., ... Brown, P. V. (2011). Results of the "Active by Choice Today" (ACT) randomized trial for increasing physical activity in low-income and minority adolescents. Health Psychology, 30(4), 463-471.

DOI: $10.1037 / \mathrm{a} 0023390$

This article may not exactly replicate the final version published in the APA journal. It is not the copy of record.

(c) Health Psychology, 2011, American Psychological Association

http://www.apa.org/pubs/journals/hea/index.aspx

This Article is brought to you by the Physical Activity and Public Health at Scholar Commons. It has been accepted for inclusion in Faculty Publications by an authorized administrator of Scholar Commons. For more information, please contact digres@mailbox.sc.edu. 


\section{Author(s)}

Dawn K. Wilson, M. Lee Van Horn, Heather Kitzman-Ulrich, Ruth P. Saunders, Russell R. Pate, Hannah G. Lawman, Brent Hutto, Sarah Griffin, Nicole Zarrett, Cheryl L. Addy, Leslie Mansard, Gary Mixon, and

Porschia V. Brown 
Published in final edited form as:

Health Psychol. 2011 July ; 30(4): 463-471. doi:10.1037/a0023390.

\title{
Results of the "Active by Choice Today" (ACT) Randomized Trial for Increasing Physical Activity in Low-Income and Minority Adolescents
}

\author{
Dawn K. Wilson, \\ Department of Psychology, University of South Carolina
}

M. Lee Van Horn,

Department of Psychology, University of South Carolina

Heather Kitzman-Ulrich,

Department of Psychology, University of South Carolina

Ruth Saunders,

Department of Health Promotion, Education and Behavior, Arnold School of Public Health, University of South Carolina

Russell Pate,

Department of Exercise Science, Arnold School of Public Health, University of South Carolina

Hannah G. Lawman,

Department of Psychology, University of South Carolina

\section{Brent Hutto,}

Prevention Research Center, Arnold School of Public Health, University of South Carolina

Sarah Griffin,

Department of Public Health Sciences, College of Health, Education, and Human Development, Clemson University

\section{Nicole Zarrett,}

Department of Psychology, University of South Carolina

Cheryl L. Addy,

Department of Epidemiology and Biostatistics, Arnold School of Public Health, University of South Carolina

\section{Leslie Mansard,}

Department of Psychology, University of South Carolina

Gary Mixon, and

Sumter County Parks and Recreation Department (ClinicalTrials.gov number NCT01028144)

\section{Porschia V. Brown}

Department of Health Promotion, Education and Behavior, Arnold School of Public Health, University of South Carolina

\section{Abstract}

\footnotetext{
(C) 2011 American Psychological Association

Correspondence concerning this article should be addressed to Dawn K. Wilson, Department of Psychology, Barnwell College, University of South Carolina, Columbia, SC 29208. wilsondk@ mailbox.sc.edu.
} 
Objective-This study reports the results of the "Active by Choice Today" (ACT) trial for increasing moderate-to-vigorous physical activity (MVPA) in low-income and minority adolescents.

Design-The ACT program was a randomized controlled school-based trial testing the efficacy of a motivational plus behavioral skills intervention on increasing MVPA in underserved adolescents. Twenty-four middle schools were matched on school size, percentage minorities, percentage free or reduce lunch, and urban or rural setting before randomization. A total of 1,563 6th grade students (mean age, 11.3 years, 73\% African American, 71\% free or reduced lunch, 55\% female) participated in either a 17-week (over one academic year) intervention or comparison after-school program.

Main Outcome Measure-The primary outcome measure was MVPA based on 7-day accelerometry estimates at 2-weeks postintervention and an intermediate outcome was MVPA at midintervention.

Results-At midintervention students in the intervention condition engaged in 4.87 greater minutes of MVPA per day (95\% CI: 1.18 to 8.57) than control students. Students in intervention schools engaged in $9.11 \mathrm{~min}$ (95\% CI: 5.73 to 12.48) more of MVPA per day than those in control schools during the program time periods; indicating a 27 min per week increase in MVPA. No significant effect of the ACT intervention was found outside of school times or for MVPA at 2weeks postintervention.

Conclusions-Motivational and behavioral skills programs are effective at increasing MVPA in low-income and minority adolescents during program hours, but further research is needed to address home barriers to youth MVPA.

\section{Keywords}

physical activity; adolescents; minorities; interventions

National studies indicate that the increasing rate of childhood obesity is a major public health problem and that prevalence rates of obesity among youth have more than tripled in the last three decades (Levi, Vinter, Laurent, \& Segal, 2008; Ogden, Carroll, Curtin, Lamb, $\&$ Flegal, 2010). Reports indicate that $34.2 \%$ of adolescents and 39.5\% of African American adolescents are overweight or obese (Ogden et al., 2010). In addition, recent estimates indicate that 50-92\% of youth do not meet the national guidelines for engaging in regular physical activity (PA) and PA declines by $50 \%$ between the elementary and middle school years (Nader et al., 2008; Troiano et al., 2008; U.S. Department of Health and Human Services, 2008). High levels of obesity have been found to be especially problematic among minority and low-income youth who have less access to safe PA opportunities, and who have lessfamily support for participating in PA (Molnar, Gortmaker, Bull, \& Buka, 2004; Pettit, Laird, Bates, \& Dodge, 1997).

Few studies have examined the effects of school-based interventions on increasing PA in underserved adolescent populations such as low income, ethnic minorities (Bayne-Smith, Fardy, Magel, Schmitz, \& Agin, 2004; Coleman, Tiller, Sanchez, et al., 2005; McKenzie et al., 2004; Robinson et al., 2003; Story et al., 2003). In general school-based interventions have had little or only modest effects on increasing PA and have resulted in little to no change in PA outside of school settings (Baranowski, Anderson, \& Carmark, 1998; Gortmaker et al., 1999; Kelder, Perry, \& Klepp, 1989; Killen et al., 1988; Saunders et al., 2006; van Sluijs, McMinn, \& Griffin, 2007). Where comprehensive school-based interventions have typically included common behavior modification components including self-monitoring of PA, goal setting, and behavioral skills training, little attention has been given to involving youth in developing program ideas and PA choices that may enhance 
more intrinsic motivation, and thus, increase the likelihood of continued engagement in PA. Previous studies have provided evidence for the importance of choice and self-initiated behavior change on increasing intrinsic motivation for engaging in PA (Ferrer-Caja \& Weiss, 2000; Thompson \& Wankel, 1980; Wilson et al., 2005), but large scale randomized trials have not tested motivational and behavioral skills interventions specifically in lowincome, ethnic minority adolescents (Wilson, 2009; Wilson et al., 2002; Wilson et al., 2005).

The ACT intervention integrated principles from Self-Determination Theory (Deci, Koestner, \& Ryan, 1999; Ryan \& Deci, 2000) and Social Cognitive Theory (Bandura, 1989, 2004). Self-Determination Theory (SDT) proposes that behavior changes that are motivated by intrinsic factors such as novel, enjoyable, self-driven, and satisfying experiences will be sustained over time. In the ACT intervention elements from SDT targeted the social environmental during the after-school program for enhancing autonomy (choice), fun, belongingness (engagement), and competence (challenges emphasizing non- competitive play) for PA (Wilson et al., 2006; Wilson et al., 2009). SCT theory assumes that individualcognitive factors, environmental events, and behavior are interacting and reciprocal determinants of each other. Thus, both cognitive and social factors were integrated into the development of a behavioral skills component of the ACT intervention for increasing PA. The ACT intervention specifically targeted development of behavioral skills (communication, reciprocity of social support, group goal setting, and behavioral competence) for increasing PA outside of program days. In addition, the ACT after-school program social environment (autonomy, choice, participation, belongingness, fun, enjoyment, support) was designed to have a positive impact on cognitive mediators (selfconfidence, perceived competence) and motivational orientation (intrinsic motivation, commitment, positive self-concept) to promote longterm PA behavior (Wilson et al., 2009, 2006, 2008). The primary aim of this study was to determine the efficacy of the motivational and behavioral skills ACT intervention (vs. a control program- general health education) on increasing PA at 2-weeks postintervention (primary outcome) and at midintervention (intermediate outcome) in underserved adolescents.

\section{Method}

\section{Study Design}

The ACT trial is a group-randomized cohort design (12 intervention, 12 comparison schools; Wilson et al., 2008). Schools were paired on school size, percentage of minorities, proportion of free and reduced lunch, and urban or rural setting before recruitment and randomization. Baseline measures were obtained by blinded measurement staff and schools were randomized to condition using computer generated random numbers after the completion of baseline measures. A total of 24 middle schools in South Carolina were recruited to participate.

\section{Recruitment}

The recruitment flowchart is presented in Figure 1. All 6th grade students in 24 public middle schools were eligible to participate if they had parental consent and agreed to study participation and random assignment (Wilson et al., 2008). A total of $71 \%$ of our final sample qualified for free or reduced lunch. Adolescents were excluded if they (1) had a medical condition that interfered with PA, (2) were developmentally delayed such that the intervention materials were not cognitively appropriate or, (3) were currently in treatment for a psychiatric disorder. Presentations to parents and students were given at the school orientations encouraging participation in the after-school program (Wilson et al., 2008). During the presentations staff presented highlights of the program including no cost for 
student participation, help with homework, having fun, and making friends at their new school. Pep rallies and homeroom visits were two methods of recruitment that were implemented during a second phase of recruitment to increase enrollment in the after-school program (Wilson et al., 2008).

\section{ACT Intervention}

All of the theoretically based elements of the ACT intervention are summarized into the ACT essential elements, which have been previously described (Wilson et al., 2009, 2008). Specifically in the present study elements from SCT and SDT were combined to develop an intervention that promoted behavioral skills (communication, reciprocity of social support, group goal setting, and behavioral competence) for PA outside the program and a social environmental approach during the after-school program for enhancing autonomy (choice), fun, belongingness (engagement), and competence (challenges emphasizing noncompetitive play) for PA. Noncompetitive play involved, for example, five-pass basketball in which all players on the team had to handle the ball before shooting. This notion here was to create a positive climate were belonging rather that winning was emphasized. Behavioral goal setting was always performed as a group and involved making a public commitment (i.e., exercise for a set amount of minutes per day in the home environment) to create belongingness and positive social support among peers in the program.

The ACT intervention was a 17-week program implemented on Mondays, Tuesdays, and Thursdays for $2 \mathrm{hr}$ after school. On Wednesdays students practiced what they had learned in the after-school program in their home environment. A trained team leader, with expertise in implementing physical activities in youth, provided the structure for the ACT intervention program implementation (see also Wilson et al., 2009, for details on training). The program had three main components: homework/snack (30 min), MVPA activities (60 min) that students selected each week, and a behavioral skills and motivational component (30 min) during which intervention staff worked with participants on developing strategies for increasing their MVPA in their home environment. The General Health Education Program (comparison program) focused on nutrition, stress management, drug prevention, and dropout prevention (with no PA component). The comparison program consisted of a homework/ snack (30 min) and three hands-on activities related to general health (30 min each). The comparison program was held on the same days and times as the ACT intervention program (Wilson et al., 2008).

\section{Measures}

The ACT intervention was 17 weeks in duration over the course of one academic school year. Measures were collected at baseline (October), midintervention (9-weeks; December) (intermediate outcome), and at 2-weeks postintervention (19-weeks; April). Process evaluation data were obtained throughout the duration of the program (Wilson et al., 2009).

Process evaluation measures-The ACT trial incorporated a comprehensive process evaluation methodology for assessing program implementation (Wilson et al., 2009, 2008). The ACT process data for this report were assessed for summative purposes and were collected by a trained, independent process evaluator using systematic observation of afterschool program activities to assess the fidelity of intervention implementation, dose delivered, and reach of the intervention (Wilson et al., 2009, 2008). The process evaluation questions can be summarized as: (1) Dose delivered (completeness for all components), To what extent were all planned components of the program provided to program participants? (2) Fidelity (for PA and behavioral skills components), To what extent was the social environment autonomy supportive, (3) Reach, What percentage of the possible target group attended each day of the program? Observational data capturing fidelity were scored on a 4 
point scale with 1 representing lowest fidelity and 4 representing highest level of fidelity. Mean scores were used to summarize the results. Fidelity measures for the PA and behavioral skills component of the program included measures for clarity of rules and expectations, choice, optimal challenge, and relatedness and belonging. The dose assessment used yes or no response options.

The process evaluator observed the 2-hr program for each day of the program for 2 weeks ( 3 program days for 2 weeks) at three points in time, early (weeks 1 and 2), midpoint (weeks 8 and 9), and near the end (weeks 15 and 16) of the 17-week program. Fidelity data were not obtained in comparison schools because of limited resources. Daily attendance was recorded by the team leader at each school (across intervention and control schools) during program days. Before implementation, the team determined that the minimal acceptable level of fidelity was 3 on a 1-4 scale. In addition, the dose criteria was based on the percentage of core activities that program staff completed during the sessions that were observed and that before implementation, the team determined that the minimum acceptable level was $75 \%$ completion.

Demographic measures-Participants' age, sex, and race were self-reported at baseline. Height and weight were assessed objectively at baseline and at 2-weeks postintervention. Information about whether students were on the free or reduced lunch was obtained from school records.

Motivational measures-The Intrinsic Motivation Inventory (IMI), a multidimensional measurement to assess participants' subjective motivational experience related to PA was measured at midintervention during the after-school program. This measure has been previously validated (Deci, Eghrari, Patrick, \& Leone, 1994). The instrument assesses participants' enjoyment, perceived competence, effort, value/usefulness, felt pressure and tension, and perceived choice while performing a given activity, thus yielding six subscale scores. The two subscales used in the present study included the: (1) interest/enjoyment subscale and (2) perceived choice subscale. These subscales were theorized to be positive predictors of both self-report and behavioral measures of intrinsic motivation and have been shown to have adequate reliability and validity (McAuley, Duncan, \& Tammen, 1987). In the present study, perceived enjoyment was a positive endorsement count of six items (yes or no format) with a mean of $4.19(S D=2.15)$ and for perceived choice was a positive endorsement count of five items (yes or no format) with a mean of $2.31(S D=1.27)$.

PA monitoring (Accelerometers)-Assessments of MVPA were obtained with omnidirectional Actical accelerometers (Mini-Mitter, Bend, OR) at baseline, midintervention, and at 2-weeks postintervention. Actical has been shown to have moderate to high correlations between activity counts and energy expenditure of individuals measured concurrently by other empirically tested accelerometers (e.g., MTI Actigraph, Caltrac, Tritrac) (Puyau, Adolph, Vohra, Zakeri, \& Butte, 2004). Participants wore an accelerometer over seven consecutive days to calculate MVPA. Each weekday of Actical data was divided into five intervals: 6-9 a.m., 9-2 p.m., 2-5 p.m., 5-8 p.m., and 8 p.m. to midnight while weekend days used intervals of 6-11 a.m. and 11 a.m. to 2 p.m. as was done in a previous national trial (Catellier et al., 2005). Data were recorded in 1-min epochs (Welk, Schaben, \& Morrow, 2004) and data was converted into time spent in moderate PA ( 3 to $<6$ METS), vigorous PA ( 6 to $<9$ METS), and MVPA ( 3 to $<9$ METS) based on Actical-specific activity count thresholds where MVPA $=1,500$ to $<6,500$ and VPA $=>6,500$ (Puyau et al., 2004). 


\section{Data Analysis}

Mixed ANCOVAs with random effects appropriate for group randomized trials were used to assess the effect of the ACT intervention (Donner \& Klar, 2000) on MVPA. Using the mixed effects notation (Pinheiro \& Bates, 2000) at 2-weeks postintervention the statistical model was:

$$
\begin{aligned}
\text { MVPApost }_{\mathrm{ij}}= & \beta_{0}+\beta_{1} \text { MVPAbase }_{\mathrm{ij}}+\beta_{2} \text { Female }_{\mathrm{ij}} \\
& +\beta_{3} \text { Black }_{\mathrm{ij}}+\beta_{4} \text { BMIbase }_{\mathrm{ij}} \\
& +\beta_{5} \text { Treatment }_{\mathrm{i}}+b_{i} \\
& +\varepsilon_{i j}, b_{i} \sim N\left(0, \sigma_{b}^{2}\right), \varepsilon_{i j} \sim N\left(0, \sigma^{2}\right)
\end{aligned}
$$

where MVPApost $\mathrm{i}_{\mathrm{j}}$ is the realized value of MVPA at 2-weeks postintervention for individual $\mathrm{j}$ in the ith school, $\beta_{0}$ is the intercept across all schools, $\beta_{1}-\beta_{4}$ are the effects of covariates (sex, ethnicity, and baseline BMI were included as covariates in all analyses where MVPA was the outcome), and $\beta_{5}$ is the difference in means between intervention and control schools holding covariates constant. The random effect $b_{i}$ allows for intercepts to differ between schools, thus accounting for any nonindependence of the outcome within schools. The random error terms are assumed to be approximately normally distributed with a mean of 0 , and variances $\sigma^{2}$ and $\sigma^{2}$, respectively. Degrees of freedom for intervention effects were constrained by the number of schools in the analyses.

An analysis was also conducted at the midintervention to test for intervention effects during the time block when the after-school program was in session. The model was modified such that the outcome variable was minutes of MVPA in each time block:

$$
\begin{aligned}
\text { MVPA }_{i j t}= & \beta_{0}+\beta_{1} \text { MVPAbase }_{\mathrm{ijt}}+\beta_{2} \text { Female }_{\mathrm{ijt}} \\
& +\beta_{3} \text { Black }_{\mathrm{ijt}}+\beta_{4} \text { BMIbase }_{\mathrm{ijt}}+\beta_{5} \text { Treatment }_{\mathrm{i}} \\
& +\beta_{6} \text { Program Time }_{\mathrm{ijt}} \\
& +\beta_{7} \text { Treatment } * \text { Program Time } \\
& +b_{0 i j}+b_{7 i j}+b_{0 i}+b_{7 i}
\end{aligned}
$$

where $i$ indicates schools, $j$ indicates individuals, and $t$ indicates time blocks. Program time takes the value 1 if time block $\mathrm{t}$ was during the after-school hours on Monday, Tuesday, or Thursday (program days) and 0 otherwise. Therefore, the parameter $\beta_{5}$ represents the difference in MVPA between intervention and control schools when students are not in the after-school program, $\beta_{6}$ is the effect of program time for the control schools, and $\beta_{7}$ is the difference in MVPA between intervention and control schools during the program time. This is now a three level model, with random effects for the intercept and the interaction between intervention and program time for individuals and for schools.

Multiple imputation was used (Schafer, 1997a) to provide unbiased parameter estimates and standard errors for the intervention effect consistent with previous national trials (Catellier et al., 2005; Murray, 1998; Taljaard, Donner, \& Klar, 2008). The PAN package (Schafer, 1997b) implemented within R (R Foundation, 2008) was used to generate 40 imputations with minutes of MVPA for each period log-transformed (for details see http://www.psych.sc.edu/facdocs/wilson.html). Imputation was conducted at the student level and baseline information for each student was included in the imputation model. If a student was missing for an entire assessment period, (e.g., midintervention) then a summary score representing average minutes of MVPA for the entire period was imputed. Time block specific imputations take advantage of information from consecutive time blocks and time of day effects present in that wave; attempting to impute time block specific effects when a 
student was not present for that assessment period was avoided because of highly variable and sometimes extreme estimates. All reported standard errors were adjusted for missing information, and reported intra class correlation coefficients (ICCs) were averaged across all imputations.

\section{Results}

\section{Baseline Analyses}

Table 1 presents the baseline demographics of the study sample. Students were on average 11.3 years old and an average had a BMI of 22.9. Fifty-four percent of the participants were female, and $73 \%$ were African American. Fifty-one percent of the youth were in the 85th percentile for being overweight or obese. Random effects models using multiply imputed data and incorporating clustering within schools found no significant differences between intervention and control schools for any of these variables. An additional random effects ANCOVA was conducted and examined differences in MVPA between intervention and control groups at baseline. Students in intervention schools engaged in 0.19 min per day less of MVPA (95\% CI: -4.60 to 4.22) than those in control schools. This result was not greater than that expected because of chance. The ICC for MVPA at baseline with covariates was . 012 .

Because the time specific analyses at midpoint included only students present during midintervention, additional analyses were conducted to evaluate differential attrition for this time point. Absence at midpoint was used to predict ethnicity, sex, baseline age, baseline BMI, and baseline MVPA using multiple imputation. No differences were found on sex, baseline BMI, or baseline MVPA. Those not present at midpoint were older than those present by .07 years (95\% CI: .002 to .145 ). There was also an effect of ethnicity on midpoint absence, African American students had a decrease in the logit of being absence at midpoint of -.40 ( $S E=.14) ; 28 \%$ of non-African American students and 23\% of African American students were absent at midintervention.

\section{Process Evaluation}

The attendance rates across intervention and control schools were very similar and has been previously reported (Wilson et al., 2009). Averaged across intervention and control schools the attendance rates were $46 \%$ for year 1, 64\% for year 2, 57\% for year 3, and 55\% for year 4. Eleven of the 12 intervention schools met the overall dose delivered criteria with at least $75 \%$ of components delivered (see Table 2). Nine of the 12 intervention schools met the fidelity criteria (3.0 or higher rating) for intervention implementation (see Table 2).

\section{Analysis of Intervention Effects on MVPA}

Midintervention-As expected, an examination of levels of MVPA across the course of the study (see Table 3) showed a seasonal effect. Levels of MVPA decreased from baseline to midintervention and increased from midintervention to 2 weeks postintervention. Furthermore, as the intervention took place on Mondays, Tuesdays, and Thursdays, it is notable that MVPA in the ACT intervention group appeared to increase from baseline on those program days. As compared to baseline, MVPA for the control group was lower at midintervention across every day. Differences in this trend between ACT and the control group were examined using a mixed effects ANCOVA, and demonstrated a significant intervention effect at midintervention (see Table 4). The ACT intervention was successful at reducing the seasonal decrease in MVPA; students in the ACT intervention engaged in 4.87 greater minutes per day of MVPA (95\% CI: 1.18 to 8.57) than those in the control condition. The effect size for this increase across the entire week is Cohen's D $=.24$. The ICC for MVPA at midintervention was .024. 
Further analyses were conducted to determine the effects at midintervention (including only students with actical data at midintervention, $N=1079$ ). An analysis was conducted with minutes of MVPA from each of the 5 time periods per day for the week at midintervention as the outcome. The program time indicator specifies that an observation was during the after-school program and the interaction between program time and treatment ("Program Time*TX", see Table 5) indicated the treatment effect on MVPA during the time that the program was in session. Results (see Table 5) demonstrated that students in the ACT intervention schools engaged in $9.11 \mathrm{~min}$ (95\% CI: 5.73 to 12.48) more of MVPA than those in control schools during the three time periods in which the after-school programs were conducted; indicating a 27 min per week increase in MVPA.

MVPA at 2-weeks postintervention-A mixed effects ANCOVA demonstrated no significant differences in MVPA between intervention and control groups at 2-weeks postintervention (see Table 4). The correlation between baseline and 2-week postintervention MVPA was $0.37, p<.05$. The ICC of the outcome was .019 , and there was little missing information.

Motivational measures during midintervention-Additional analyses were conducted to look at differences between ACT and control schools student perceptions of enjoyment and choice of activities based on the IMI subscales (Deci, Eghrari, Patrick \& Leone, 1994) at midintervention during the after-school program. A mixed effects ANCOVA demonstrated a significant intervention effect such that students in the ACT program reported higher levels of program enjoyment than students in the control program (B = .69, $S E=.29, d f=22 ; p<.05)$. Students in the ACT intervention also reported having greater choice of activities than students in the control program $(\mathrm{B}=.69, S E=.29, d f=22$; $p<.05)$. The effect sizes for both effects were Cohen's D of .32 and .29, respectively.

\section{Postintervention Focus Groups}

At postintervention three focus groups were conducted with students ( $n=19$ students) at two ACT intervention schools to determine what barriers prevented youth from continuing PA after the program ended. Students reported four themes related to barriers (1) competing demands at home, (2) not being motivated without teachers, (3) lack of parent involvement such as "could not go outside because parents were not home" and "parents made it hard to exercise at home," and (4) environmental barriers such as "bad weather" and "safety concerns."

\section{Discussion}

This is the first randomized trial to demonstrate a significant effect of increasing MVPA in low-income and ethnic minority adolescents in an after-school program using carefully measured accelerometry estimates. The intervention youth demonstrated a significant increase in MVPA as compared to control students at midintervention, however, the intervention effects were not sustained at 2-weeks postintervention. Focus group data indicated that these youth had a number of barriers in the home environment and in particular parents lack of involvement made it hard for them to continue engaging in PA.

Students in the intervention schools engaged in significantly greater minutes of MVPA per day than those in the control schools at midintervention. This finding is consistent with McKenzie et al. (2004) who evaluated a school-based physical education intervention on increasing MVPA in middle school students (55\% minorities). The 2 year intervention resulted in a 3 min per session increase in MVPA based on observational evaluation methods of lessons. Our results indicated an approximate 9 min increase per day in MVPA 
across program days, which was somewhat greater than the increase observed in McKenzie's et al. (2004) study. The weekly increase in the present study was equivalent to a 27 min increase in MVPA which is clinically meaningful in that it could shift youth into a higher level of health benefit based on national recommendations (Dunn et al., 1999). Although other investigators have conducted school programs to increase MVPA, they have not focused on low-income or minority populations (Simon et al., 2008) and many studies have not demonstrated intervention effects in school-based settings (Baranowski, Anderson, \& Carmark, 1998; Beet, Bieghle, Erwin, \& Huberty, 2009; McKenzie \& Lounsbery, 2009; Salmon et al., 2007; van Sluijs, McMinn, \& Griffin, 2007). Our trial further expands on previous research by utilizing accelerometry estimates rather than relying on self-report data (Beet et al., 2009).

The lack of an effect of increasing MVPA beyond the school environment is consistent with other studies that have shown substantial barriers for PA in underserved youth (MongeRojas, Garita-Arce, Sanchez-Lopez, \& Colon-Ramos, 2009). Minority and low-income youth have been shown to have less access to safe and well-resourced PA opportunities (Molnar et al., 2004), have less family support, and greater barriers for participating in regular PA (Molnar et al., 2004; Pettit et al., 1997). Future interventions for underserved youth need to intervene in multiple contexts, such as in the school and home settings simultaneously to develop cost-effective programs that go beyond the school setting. A multiple systems approach that includes school and home environments could have a synergistic impact on increasing MVPA in underserved youth. Although some interventions have incorporated school and family components in promoting increases in PA among youth (Luepker et al., 1996; Manios, Kafatos, \& Mamalakis, 1998; Sallis et al., 1997; Story et al., 2003; Warren et al., 2003) few studies have specifically done so in adolescents' (Salmon et al., 2007) and few have focused on underserved populations or have used objective measures of PA (Beet et al., 2009). Most multilevel school and family based programs have not been effective for promoting PA and have not been design to directly test synergistic effects (Caballero et al., 2003; Coleman et al., 2005; Fitzgibbon et al., 2005; Goran \& Reynolds, 2005; Paradis et al., 2005).

Few studies have adequately reported dose and fidelity estimates of program implementation (Beet et al., 2009). One issue that requires further investigations is attendance rates, as some research has demonstrated, that students who attend $40 \%$ or greater of PA sessions show greater increases in physical fitness (Gutin, Yin, Johnson, \& Barbeau, 2008; Yin et al., 2005). In the ACT trial, analyses that considered differential attendance rates did not change the overall findings presented in this report. Based on the current "state of the art" it appears that school level randomization has been lacking and extensive assessment of PA through accelerometry measures and follow up have been limited. Given that the ACT trial addressed all of these issues it provides a standard on which to promote future research efforts especially in underserved youth who are at increased risk of developing obesity and who have a number of barriers in the home environment that may limit opportunities to engage in regular PA.

There are limitations to the present study that should be noted. As summarized in this study, the dose and fidelity estimates during the first year of schools were not adequate which may have weakened the overall effects reported. However, our analytical methods using multiple imputations allowed us to utilize the maximum amount of information possible to evaluate intervention effects. Further research is needed that continues to utilize these methods for capturing missing values in an unbiased manner with accelerometry measures in youth.

This study provides evidence that a novel integration of motivational and behavioral skills into an after-school intervention was effective in increasing MVPA during the intervention 
period in low-income, ethnic minority youth, but not at 2-weeks postintervention. Our study indicated a threefold great effect of the intervention on increasing MVPA than previous studies that included minority youth (McKenzie et al., 2004). Qualitative data revealed a number of barriers in the home including lack of parental involvement. Thus, future interventions are needed to intervene in multiple contexts, such as in the school and home settings simultaneously, to develop a potential synergistic impact of programs in underserved youth. Consistent with recent national recommendations for prevention of childhood obesity (Davis et al., 2007) our ACT trial used a rigorous approach to increase PA in low-income and ethnic minority adolescents. Given the alarming rates of obesity and risk for morbidity and premature mortality in this underserved population, this study sets the stage for continued scientific investigation to further enhance the impact and effects of interventions beyond the school setting on improving the health outcomes in low-income and minority youth.

\section{Acknowledgments}

This article was supported by a grant (R01 HD 045693) funded by the National Institutes of Child Health and Human Development to D. K. W.

\section{References}

Bandura, A. Social foundations for thought and action. Prentice Hall; Englewood Cliffs, NJ: 1986.

Bandura A. Health promotion by social cognitive means. Health Education and Behavior. 2004; 31:143-164. [PubMed: 15090118]

Baranowski T, Anderson C, Carmark C. Mediating variables framework in physical activity interventions. How are we doing? How might we do better? American Journal of Preventive Medicine. 1998; 15:266-297. [PubMed: 9838973]

Bayne-Smith M, Fardy PS, Magel J, Schmitz K, Agin D. Improvements in heart health behaviors and reduction in coronary artery disease risk factors in urban teenaged girls though a school-based intervention: The PATH Program. American Journal of Public Health. 2004; 94:1538-1543. [PubMed: 15333311]

Beet MW, Bieghle A, Erwin HE, Huberty JL. Afterschool program impact on physical activity and fitness: A meta analysis. Journal of Preventive Medicine. 2009; 36:527-537.

Caballero B, Clay T, Davis SM, Ethelbah B, Rock BH, Lohman T, Pathways, ... Study Research Group. Pathways: A school-based, randomized controlled trial for the prevention of obesity in American Indian schoolchildren. American Journal of Clinical Nutrition. 2003; 78:1030-1038. [PubMed: 14594792]

Catellier DJ, Hannan PJ, Murray DM, Addy CL, Conway TL, Yang S, Rice JC. Imputation of missing data when measuring physical activity by accelerometry. Medicine, Science, Sports and Exercise. 2005; 37(Suppl):S555-S562.

Coleman KJ, Tiller CL, Sanchez J, Heath EM, Ouman S, Milliken G, Dzewaltowski DA. Prevention of the epidemic increase in child risk of overweight in low-income schools. Archives of Pediatric Adolescent Medicine. 2005; 159:217-224.

Davis MM, Gance-Cleveland B, Hassink S, Johnson R, Paradis G, Resnicow K. Recommendations for prevention of childhood obesity. Pediatrics. 2007; 120:5229-5252.

Deci EL, Eghrari H, Patrick BC, Leone D. Facilitating internalization: The self-determination theory perspective. Journal of Personality. 1994; 62:119-142. [PubMed: 8169757]

Deci EL, Koestner R, Ryan RM. A meta-analytic review of experiments examining the effects of extrinsic rewards on intrinsic motivation. Psychological Bulletin. 1999; 125:627-668. [PubMed: 10589297]

Donner, A.; Klar, N. Design and analysis of cluster randomized trials in health research. Oxford University Press; London: 2000. 
Dunn AL, Marcus BH, Kampert JB, Garcia ME, Harold WK, Blaire SN. Comparison of lifestyle and structured interventions to increase physical activity and cardiorespiratory fitness: A randomized trial. Journal of the American Medical Association. 1999; 281:327-334. [PubMed: 9929085]

Ferrer-Caja E, Weiss MR. Predictors of intrinsic motivation among adolescent students in physical education. Research Quarterly Exercise and Sports. 2000; 71:267-279.

Fitzgibbon ML, Stolley MR, Schiffer L, Van Horn L, Kaufer-Christoffel K, Dyer A. Two-year followup results for Hip-Hop to Health Jr. A randomized controlled trial for overweight prevention in preschool minority children. Journal of Pediatrics. 2005; 146:618-625.

Goran ML, Reynolds K. Interactive multimedia for promoting physical activity (IMPACT) in children. Obesity Research. 2005; 13:762-771. [PubMed: 15897486]

Gortmaker SL, Peterson K, Wiecha J, Sobol AM, Dixit S, Fox MK, Laird N. Reducing obesity via a school-based interdisciplinary intervention among youth: Planet health. Archives of Pediatric and Adolescent Medicine. 1999; 153:409-418.

Gutin B, Yin Z, Johnson M, Barbeau P. Preliminary findings of the effect of a 3 year after-school physical activity intervention on fitness and body fat: The Medical College of Georgia FitKid Project. International Journal of Pediatric Obesity. 2008; 3(Suppl. 1):3-9. [PubMed: 18278626]

Kelder SH, Perry CL, Klepp KI. Community-wide youth exercise promotion: Long-term outcomes of the Minnesota Heart Health Program and the Class of 1989 study. Journal of School Health. 1989; 63:218-223. [PubMed: 8336479]

Killen JD, Telch MJ, Robinson TN, Maccoby N, Taylor CB, Farquhar JW. Cardiovascular disease risk reduction for tenth graders: A multiple-factor school-based approach. Journal of the American Medical Association. 1988; 260:1728-1733. [PubMed: 3411756]

Levi J, Vinter S, Laurent R, Segal LM. F as in fat: How obesity policies are failing in America. Trust for American Health Issue Report. 2008 Retrieved from http//healthyamericans.org/reports/ obesity2008/Obesity2008Report.pdf.

Luepker RV, Perry CL, McKinlay SM, Nader PR, Parcel GS, Stone EJ, Verter J. Outcome of a field trial to improve children's dietary patterns and physical activity. The Child and Adolescent Trial for Cardiovascular Health (CATCH). Journal of the American Medical Association. 1996; 275:768-776. [PubMed: 8598593]

Manios Y, Kafatos A, Mamalakis G. The effects of a health education intervention initiated at first grade over a 3 year period: Physical activity and fitness indices. Health Education Research. 1998; 1:593-606. [PubMed: 10345909]

McAuley E, Duncan T, Tammen VV. Psychometric properties of the Intrinsic Motivation Inventory in a competitive sport setting: A confirmatory factor analysis. Research Quarterly for Exercise and Sport. 1987; 60:48-58. [PubMed: 2489825]

McKenzie T, Sallis JF, Prochaska JJ, Conway TL, Marshall SJ, Rosengard P. Evaluation of a two-year middle school physical education intervention: M-SPAN. Medicine, Science, Sports and Exercise. 2004; 94:1382-1388.

McKenzie TL, Lounsbery MA. School physical education: The pill not taken. American Journal of Lifestyle Medicine. 2009; 3(3):219-225.

Molnar BE, Gortmaker SL, Bull FC, Buka SL. Unsafe to play? Neighborhood disorder and lack of safety predict reduced physical activity among urban children and adolescents. American Journal of Health Promotion. 2004; 18:378-386. [PubMed: 15163139]

Monge-Rojas R, Garita-Arce C, Sanchez-Lopez M, Colon-Ramos U. Barriers to and suggestions for a healthful, active lifestyle as perceived by rural and urban Costa Rican Adolescents. Journal of Nutrition, Education and Behavior. 2009; 41:152-160. [PubMed: 19411048]

Murray, DM. Design and analysis of group-randomized trials. Vol. Vol. 27. Oxford University Press; New York: 1998.

Nader PR, Bradley RH, Houts RM, McRitchie SL, O'Brian M. Moderate-to-vigorous physical activity from ages 9 to 15 years. Journal of the American Medical Association. 2008; 300:295-305. [PubMed: 18632544]

Ogden CL, Carroll MD, Curtin LR, Lamb MM, Flegal KM. Prevalence of high body mass index in US children and adolescents, 2007-2008. Journal of the American Medical Association. 2010; 303:242-249. [PubMed: 20071470] 
Paradis G, Levesque L, Macauley AC, Cargo M, McComber A, Kirby R, Potvin L. Impact of a diabetes prevention program on body size, physical activity, and diet among Kanien'keha:ka (Mohawk) children 6 to 11 years old: 8-year results from the Kahnawake Schools Diabetes Prevention Project. Pediatrics. 2005; 115:333-339. [PubMed: 15687441]

Pettit GS, Laird RD, Bates JE, Dodge KA. Patterns of after-school care in middle childhood: Risk factors and developmental outcomes. Merrill-Palmer Quarterly. 1997; 43:515-538.

Pinheiro, JC.; Bates, DM. Mixed-Effects Models in S and S-plus. Springer; New York: 2000.

Puyau MR, Adolph AL, Vohra FA, Zakeri I, Butte NF. Prediction of activity energy expenditure using accelerometers in children. Medicine and Science in Sports and Exercise. 2004; 36:1625-1631. [PubMed: 15354047]

R Development Core Team. A language and environment for statistical computing. R Foundation for Statistical Computing; Vienna: 2008.

Robinson TN, Killen JD, Kraemer HC, Wilson DM, Matheson DM, Haskell, Varady A. Dance and reducing television viewing to prevent weight gain in African American girls: The Stanford GEMS pilot study. Ethnicity and Disease. 2003; 13(Suppl):S165-S177.

Ryan RM, Deci EL. Self-determination theory and the facilitation of intrinsic motivation, social development, and well-being. American Psychologist. 2000; 55:68-78. [PubMed: 11392867]

Sallis J, McKenzie T, Alcaraz J, Kolody B, Faucette N, Hovell MF. The effects of a 2-year physical education program (SPARK) on physical activity and fitness in elementary school students. American Journal of Public Health. 1997; 87:1328-1334. [PubMed: 9279269]

Salmon J, Booth ML, Phongsavan P, Murphy N, Timperio A. Promoting physical activity participation among children and adolescents. Epidemiologic Reviews. 2007; 29:144-159. [PubMed: 17556765]

Saunders RP, Ward D, Felton GM, Dowda M, Pate RR. Examining the link between program implementation and behavior outcomes in a lifestyle education activity program (LEAP). Evaluation and Program Planning. 2006; 29:352-364. [PubMed: 17950863]

Schafer, JL. Analysis of incomplete multivariate data. Wiley; New York: 1997a.

Schafer, JL. PAN: Multiple imputation for multivariate panel data, software library written for SPLUS. 1997b.

Simon C, Schweitzer B, Oujaa M, Wagner A, Arveiler D, Triby E, Copin N, Platat C. Successful overweight prevention in adolescents by increasing physical activity: A 4-year randomized controlled intervention. International Journal of Obesity (London). 2008; 32:1489-1498.

Story M, Sherwood NE, Himes JH, Davis M, Jacobs DR Jr. Cartwright Y, Rochon J. An after-school obesity prevention program for African-American girls: The Minnesota GEMS pilot study. Ethnicity and Disease. 2003; 13(Suppl):S154-S164.

Taljaard M, Donner A, Klar N. Imputation strategies for missing continuous outcomes in cluster randomized trials. Biometrical Journal. 2008; 50:329-345. [PubMed: 18537126]

Thompson CE, Wankel LM. The effect of perceived activity choice upon frequency of exercise behavior. Journal of Applied Social Psychology. 1980; 10:436-443.

Troiano RP, Berrigan D, Dodd KW, Masse LC, Tilert T, McDowell M. Physical activity in the United States measured by accelerometry. Medicine, Science, Sports and Exercise. 2008; 40:181-188.

U.S. Department of Health and Human Services. Physical activity guidelines advisory committee report. U.S. Department of Health and Human Services; Washington, DC: 2008.

van Sluijs EM, McMinn AM, Griffin SJ. Effectiveness of interventions to promote physical activity in children and adolescents: Systematic review of controlled trials. British Medical Journal. 2007; 335:703-707. [PubMed: 17884863]

Warren JM, Henry CJK, Lightowler HJ, Bradshaw SM, Perwaiz S. Evaluation of a pilot school programme aimed at the prevention of obesity in children. Health Promotion International. 2003; 18:287-296. [PubMed: 14695360]

Welk GJ, Schaben JA, Morrow JR Jr. Reliability of accelerometry-based activity monitors: A generalizability study. Medicine, Science, Sports and Exercise. 2004; 36:1637-1645.

Wilson DK. New perspectives on health disparities and obesity in youth. Journal of Pediatric Psychology. 2009; 34:231-244. [PubMed: 19223277] 
Wilson DK, Evans AE, Williams J, Mixon G, Sirard JR, Pate RR. A preliminary test of a studentcentered intervention on increasing physical activity in underserved adolescents. Annals of Behavioral Medicine. 2005; 30:119-124. [PubMed: 16173908]

Wilson DK, Friend R, Teasley N, Green S, Reaves IL, Sica DA. Motivational versus social cognitive interventions for promoting fruit and vegetable intake and physical activity in African American adolescents. Annals of Behavioral Medicine. 2002; 24:310-319. [PubMed: 12434942]

Wilson DK, Griffin S, Saunders R, Kitzman-Ulrich H, Meyers D, Mansard L. Using process evaluation for program improvement in dose, fidelity, and reach: The ACT experience. Internal Journal of Behavioral Nutrition and Physical Activity. 2009; 6:79.

Wilson DK, Griffin S, Saunders R, Evans A, Mixon G, Wright M, Freelove J. Formative evaluation for developing a motivational intervention for increasing physical activity in youth. Evaluation and Program Planning. 2006; 29:260-268. [PubMed: 21048891]

Wilson DK, Kitzman-Ulrich H, Williams JE, Saunders R, Griffin S, Pate R, Sisson SB. An overview of the Active by Choice Today (ACT) trial for increasing physical activity. Contemporary Clinical Trials. 2008; 29:21-31. [PubMed: 17716952]

Yin Z, Gutin B, Johnson MH, Hanes J, Moore JB, Cavnar M, Barbeau P. An environmental approach to obesity prevention in children: Medical College of Georgia FitKid Project year 1 results. Obesity Research. 2005; 13:2153-2161. [PubMed: 16421350] 


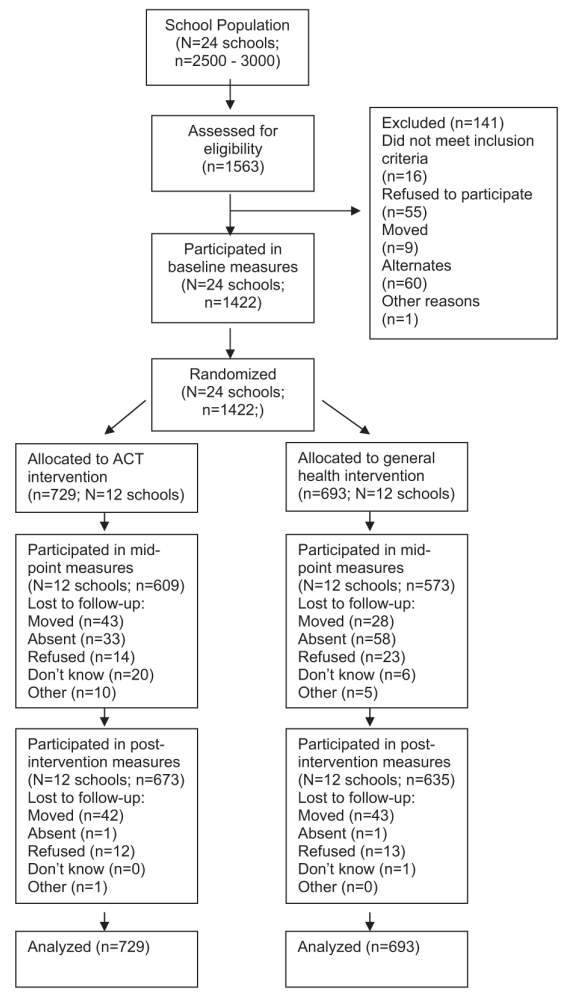

Figure 1.

Recruitment flowchart. 
Table 1

Demographic and Baseline Characteristics

\begin{tabular}{lcc}
\hline Characteristic & $\begin{array}{c}\text { Intervention } \\
(\boldsymbol{n}=\mathbf{7 2 9})\end{array}$ & $\begin{array}{c}\text { Control } \\
(\boldsymbol{n}=\mathbf{6 9 3})\end{array}$ \\
\hline Age, years, mean $(S D)$ & $11.32(0.56)$ & $11.36(0.61)$ \\
Girls, number $(\%)$ & $407(55.83)$ & $363(52.38)$ \\
African American, number $(\%)$ & $557(76.41)$ & $481(69.41)$ \\
Waist, cm, mean $(S D)$ & $70.88(12.40)$ & $71.15(12.36)$ \\
BMI, kg/m ${ }^{2}$, mean $(S D)$ & $22.80(6.16)$ & $22.86(5.88)$ \\
\hline
\end{tabular}

Notes. Demographic characteristics were calculated using nonimputed data. 


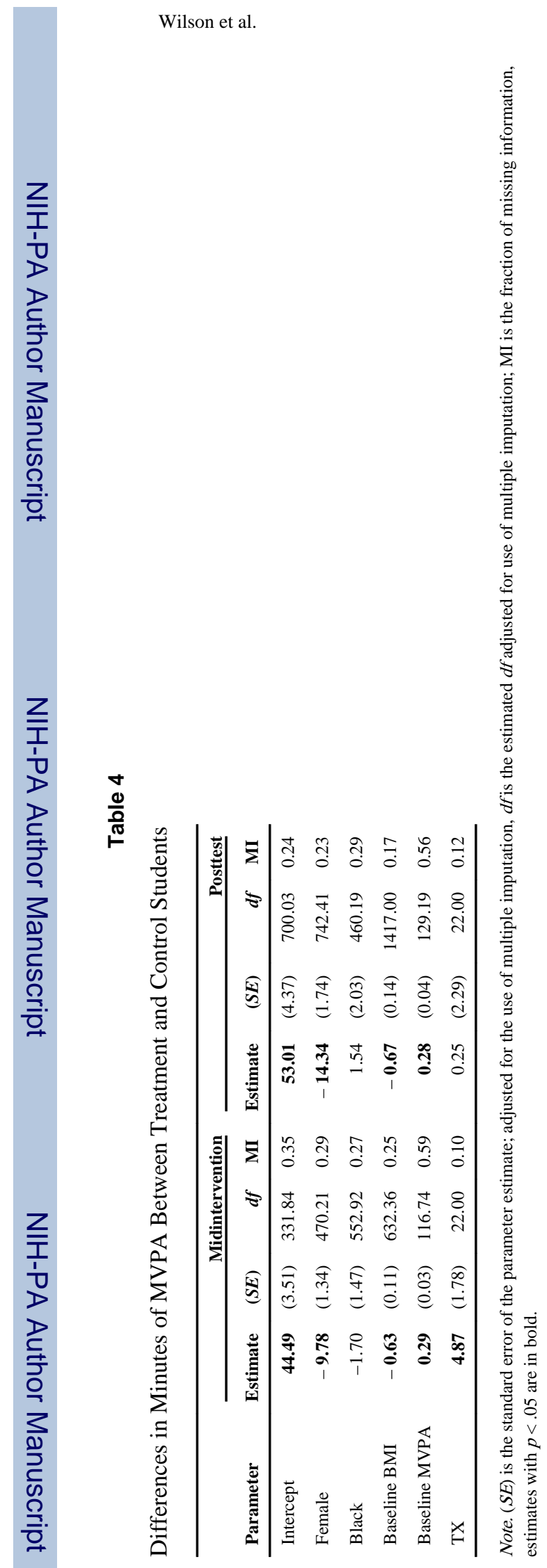

Health Psychol. Author manuscript; available in PMC 2012 August 13. 


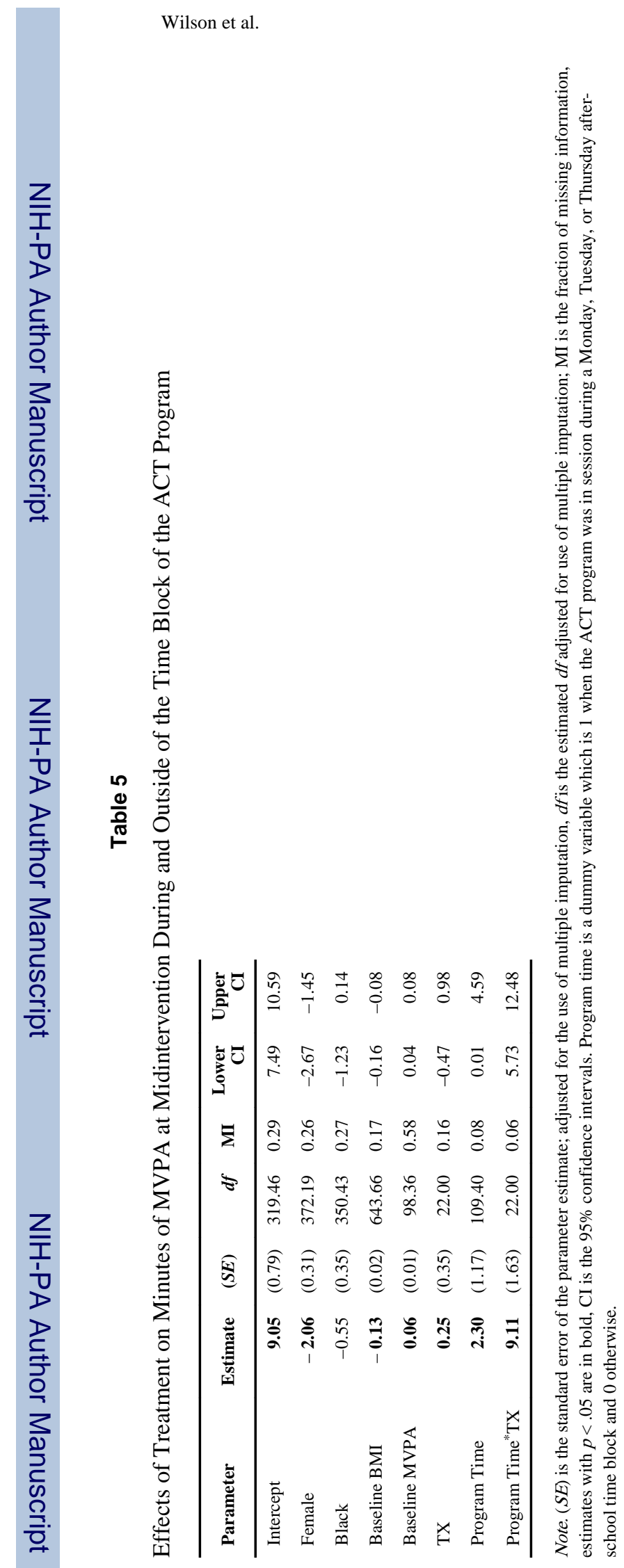

Health Psychol. Author manuscript; available in PMC 2012 August 13. 